\title{
ENCAIXES, DESENCAIXES E BLOQUEIOS: SOCIOLOGIA E EDUCAÇÃO NO BRASIL DA DÉCADA DE 1950
}

\section{Simone Meucci}

Doutora em sociologia pela Universidade Estadual de Campinas, professora do Departamento de Sociologia da Universidade Federal do Paraná. E-mail: simonemeucci2010@gmail.com

Orcid: 0000-0003-3148-4418

http://dx.doi.org/10.1590/0102-077098/110

Este artigo analisa a relação entre educação e sociologia no Brasil sob uma perspectiva histórica que privilegia a década de 1950. O texto se inspirou em três aspectos que, em conjunto, compõem um panorama inquietante acerca da percepção sobre o modo como a educação se constitui como uma questão para a sociologia no Brasil.

O primeiro aspecto refere-se aos balanços da área de sociologia da educação no Brasil, que vem sendo frequentemente qualificada nessas revisões como uma ausência, um esquecimento, uma rejeição, um ocultamento e, na melhor das possibilidades, uma escassez (Cunha, 1992; Neves, 2002; Martins e Weber, 2010; Sobral, 2013; Oliveira e Silva, 2016). Ou seja, trata-se de uma área que, segundo alguns estudos, não se constituiu em toda a sua potencialidade, considerada mais ou menos marginal no conjunto das especialidades da sociologia.

O segundo aspecto refere-se a um traço muito singular: o de que se trata de refletir não apenas acerca do estatuto da sociologia da educação, mas também da sociologia na educação (em especial na educação básica), posto que sua presença nos currículos escolares é parte substantiva de uma discussão sobre o lugar social da sociologia na sociedade. Nesse caso, diferentemente da escassez ou do esquecimento, 
tem sido notável o esforço de problematizar sua intermitência, investigando condições e expectativas que justificariam a entrada e a exclusão da sociologia dos currículos obrigatórios de escolas ao longo da história republicana do Brasil (Moraes, 2003, p. 6).

Por fim, o terceiro aspecto a ser lembrado é de que a educação escolar, no Brasil, é sempre uma esperança que não se constitui, porém, como um direito efetivamente universalizado. Nesse caso, estamos diante da intermitência e da escassez do projeto democrático, o que impõe condições muito limitadas para circulação e apropriação do conhecimento produzido, problema que é duplamente problemático para a sociologia e para sociólogos e sociólogas por travar, a um só tempo, expectativas profissionais e utopias sociais.

Essas três dimensões apresentam diferentes faces da tensão na relação entre sociologia e educação. Referem-se, a um só tempo, a dimensões heurísticas e sociopolíticas. Por esse motivo, orientaram a escolha de três eixos empíricos para o desenvolvimento dos argumentos neste artigo: a) as investigações da Unesco no período da rotinização das pesquisas sociológicas no Brasil; b) o debate sobre sociologia no ensino médio envolvendo, desde o final dos anos 1940 e início dos 1950, alguns dos primeiros portadores especializados da área; c) os debates, no período, acerca da tramitação da Lei de Diretrizes e Bases da Educação no Brasil. Esses eixos temáticos serão vistos como influxos coetâneos e recíprocos, como cenas que ocorrem mais ou menos ao mesmo tempo e que têm os mesmos personagens.

A hipótese que nos orientou no início do trabalho é de que a educação esteve no horizonte da preocupação dos sociólogos e sociólogas no país e de que tivemos, no período, investigações sociológicas relevantes nas escolas, ainda que o tema não fosse propriamente a educação no sentido estrito do termo. Suspeitamos que temas relacionados à persistência de padrões de dominação social do passado fizeram com 
que pesquisas e debates relativos ao sistema educacional e à socialização escolar se subordinassem à problematização das relações raciais e à reflexão sobre os bloqueios para a mudança social.

\section{0 projeto Unesco e a escola como unidade empírica de análise}

No Brasil dos anos 1950, numa democracia trôpega, ainda que houvesse ambições desenvolvimentistas e uma imagem positiva mais ou menos estável de nação mestiça, dados da realidade eram incontornáveis e denunciavam entraves desafiadores para essas aspirações e representações. Uma das evidências era o alto índice de analfabetismo que, no início da década, atingia quase $50 \%$ da população maior de quinze anos (Souza, 1999, p. 172). Levantamentos do período mostravam também enormes diferenças entre negros e brancos no que tange à permanência na escola: se a média nacional era cerca de 2,7 anos para crianças brancas, entre pardos o tempo reduzia para 1,2 ano, e entre negros não completava sequer um ano (PNUD/Ipea, 1996).

Os impasses da desigualdade social e racial, mascarados durante o regime do Estado Novo e desafiados pelo desenvolvimento acelerado das décadas seguintes, assumiram, pouco a pouco, um lugar no debate social. ${ }^{1}$ Estava em curso uma nova interpretação sobre o Brasil que contrastava com a formulação culturalista da identidade nacional, legado do ensaísmo dos anos 1930.

No campo dos estudos sociológicos, sabemos que também a agenda da Unesco favoreceu o confronto entre

\footnotetext{
1 Houve um episódio ocorrido em 1950 na cidade de São Paulo que aqueceu o debate sobre a natureza de nossas relações raciais. Em turnê pelo Brasil, a coreógrafa afro-estadunidense Katherine Dunham foi impedida de se hospedar no Hotel Esplanada. O ativismo e o reconhecimento artístico de Dunham transformaram a situação em escândalo, possibilitando que, no ano seguinte, fosse aprovado, no Congresso, o primeiro estatuto antidiscriminação racial do Brasil, conhecido como Lei Afonso Arinos (Andrews, 1997, p. 101).
} 
interpretações, especialmente com o desenvolvimento de pesquisas sistemáticas sobre as relações raciais no Brasil. Marcos Maio (1999) descreve em detalhes todo o percurso de elaboração do que convencionamos chamar de "projeto Unesco": desde 1949, quando houve as primeiras reivindicações de Arthur Ramos (então diretor do Departamento de Ciências Sociais da Unesco) para o desenvolvimento de estudos empíricos no Brasil, passando pela aprovação da proposta na $5^{\mathrm{a}}$ sessão da Conferência Geral do órgão em Florença (ocorrida poucos meses após a morte de Ramos), até as negociações de Alfred Metraux (o novo diretor do Departamento de Ciências Sociais) com pesquisadores ${ }^{2}$ para delinear o campo empírico nas cidades de São Paulo, Recife, Rio de Janeiro e Salvador.

Em São Paulo foi feito um acordo entre Unesco e Revista Anhembi para o patrocínio das investigações. ${ }^{3}$ Ali as pesquisas ocorreram no período entre 1951 e 1952, e dois dos estudos 80 que compuseram esse projeto elegeram o ambiente escolar como locus privilegiado de análise: os trabalhos de Virginia Bicudo e Aniela Ginsberg.

2 Entre os quais Charles Wagley, Luiz Aguiar da Costa Pinto, Roger Bastide, Otto Klineberg e Gilberto Freyre (Maio, 1999, pp. 144-147).

3 Uma polêmica provocada por Paulo Duarte, conhecido jornalista paulistano, em artigo para $O$ Estado de S. Paulo em 1947, abriu a possibilidade para o acordo entre Unesco e Revista Anhembi. No artigo, Duarte descreveu episódios de violência de negros contra brancos, interpretando-os como uma explosão de recalques após o afrouxamento dos meios de controle do Estado Novo. Para ele, ocorria a emergência de um novo fenômeno - o "problema do negro" - que demandava a retomada da responsabilidade do Estado para organizar a sociedade (Bastos, 2007, p. 254). Manifestações contrárias à opinião de Duarte foram numerosas. Sensível às questões postas, quando esteve no comando da Revista Anhembi no final da década, Duarte propôs que a publicação patrocinasse um inquérito sobre as relações raciais na cidade de São Paulo, tarefa para a qual convidou Roger Bastide e Florestan Fernandes. No mesmo período, houve o interesse da Unesco pelo tema, resultando na união dos esforços. Nesse sentido, vale ressaltar que havia efetivamente tensões e uma luta antirracista no Brasil do final dos anos 1940 e início dos 1950, que podem ser ainda evidenciadas pela criação do Teatro Experimental do Negro em 1944, para citar apenas mais um fato significativo (Nascimento, 2004). 
Virginia Bicudo (1910-2003) era uma mulher negra, criada no bairro da Luz em São Paulo, filha de funcionário dos Correios. Estudou na Escola Normal Caetano de Campos e, depois, fez curso de educação sanitária no Instituto de Higiene de São Paulo, período no qual se aproximou da psicologia social (Maio, 2010, p. 312; Santos, 2018, p. 196). Atuou como professora e também como educadora sanitária antes de fazer o curso de ciências sociais na Escola Livre de Sociologia e Política, onde também concluiu, em 1945, seu mestrado com uma pesquisa sobre relações raciais intitulada "Estudo de atitudes raciais de pretos e mulatos em São Paulo”. Sua dissertação pioneira antecipou conclusões dos estudos que se desenvolveram nos anos seguintes, ao afirmar que cor é importante componente da desigualdade social no Brasil (Maio, 2010, p. 325).

Aniela Ginsberg (1902-1986) era polonesa de origem, de uma família judaica de abastados empresários e banqueiros, formada na universidade de Varsóvia, com mestrado em filosofia e doutorado em psicologia. Chegou ao Brasil em 1936 e logo se vinculou a pesquisas sobre aplicação de testes psicológicos na Escola Caetano de Campos. Trabalhou ainda no Instituto de Organização do Trabalho de São Paulo e no Senai, coordenando atividades de orientação profissional. Além disso, ministrou aulas na Escola Livre de Sociologia e Política. Na década de 1940, morou também na Bahia e no Rio de Janeiro, onde atuou na Faculdade de Medicina e no Departamento Nacional de Ciência, respectivamente. Por fim, voltou a São Paulo, onde trabalhou para o projeto Unesco e, depois, lecionou na Universidade Católica (Cunha e Santos, 2014, p. 319; Maio, 2015).

Ambas se aproveitaram da institucionalidade criada pelo impulso modernizador dos anos 1930 e das escassas oportunidades emergentes para as mulheres em São Paulo. Atuaram também na confluência entre psicologia social e ciências 
sociais possibilitada especialmente pelas abordagens e diálogos no interior da Escola Livre de Sociologia e Política. ${ }^{4}$

Para o projeto Unesco/Revista Anhembi, Bicudo investigou 130 classes de $3^{\circ}$ ano e aplicou 4.520 questionários para indagar acerca dos sentimentos e atitudes relacionados à cor dos pequenos estudantes em sala de aula. De início, procurou perscrutar ao lado de quem os estudantes preferiam se sentar durante as aulas, verificando que crianças negras e pardas eram mais rejeitadas como parceiros de assento do que brancas. Em seguida, pormenorizou a trajetória dos trinta estudantes mais rejeitados por meio de entrevistas com os pais e professores. O estudo, por fim, demonstrou que os ideais de "bom aluno" e "mau aluno" estão atravessados pelo preconceito racial; com isso, a vivência escolar produzia, nos negros e mulatos, efeitos sociais e psíquicos que, ao contrário de combater, acabava por confirmar estereótipos. Bicudo constatou, pois, um círculo perverso de interiorização do preconceito dos brancos nas crianças negras:

Os estudantes negros foram encontrados de um lado na situação de ser considerados ruins, vagabundos, ladrões, briguentos e de outro, sob a exigência de "tornarem-se brancos", isto é, bons e eficientes cumpridores dos deveres sociais. Vivendo o conflito de ser negro e não querer ser negro, equivalente ao conflito de ser bom e ser mau, pela introjeção dos conceitos do branco, frequentemente as pessoas de cor sucumbem ao conflito, autopunitivamente exibindo traços de personalidade que se tornam como confirmação do estereótipo que lhe são atribuídos. (Bicudo, 1955, p. 269)

\footnotetext{
4 Marcos Chor Maio (2015) procurou demonstrar o processo de inflexão de Ginsberg que, de início, mobilizava tão somente a abordagem comportamentalista, passando, ao longo de sua trajetória, a lançar mão de argumentos socioantropológicos para a compreensão das desigualdades sociais.
} 
O estudo empreendido por Aniela Ginsberg, por sua vez, analisou atitudes raciais de 208 crianças em escolas primárias de diferentes bairros de São Paulo. Ginsberg lançou mão de um método aplicado em duas etapas: a primeira envolvia a escolha, pelas crianças, de vestidos e casas de diferentes qualidades para uma boneca branca e outra boneca negra; na segunda etapa, pedia às crianças a interpretação de diferentes imagens nas quais brancos e negros apareciam interagindo. Ao avaliar os testes, ela concluiu o seguinte:

Todos os examinados sem diferenças de idade, sexo, meio social ou cor mostram nos jogos marcada preferência pelos brancos - a boneca e as crianças brancas nos quadros. A boneca branca é o ideal de beleza para as crianças de todos os grupos. [...] As crianças pretas conservam o ideal branco considerando os brancos como mais bonitos e privilegiados. [...] Em geral as respostas das crianças de cor diferem muito pouco das dos brancos. (Ginsberg, 1955, p. 340)

Observemos que, em ambos os estudos, de Bicudo e Ginsberg, a escola aparece como lugar onde se expressam padrões de preconceito de cor fortemente consolidados. Nesse sentido, a discriminação parece ser resultado de processos de socialização que precedem a vivência escolar, mas que encontram ali formas de expressão, agravadas pela eficiente introjeção simbólica do preconceito do branco na criança negra.

Do conjunto de trabalhos para a Unesco que consideramos pertinente destacar para as finalidades deste artigo, vale ao menos fazer notar as observações de Luiz Aguiar da Costa Pinto, autor de O negro no Rio de Janeiro (1953), livro que é resultado de suas investigações no Distrito Federal (então no Rio de Janeiro) no mesmo período. Costa Pinto constata um efeito ambíguo da ampliação, ainda que tímida, das oportunidades escolares na cidade: uma perversa diferenciação entre negros. 
Ele identifica, pois, que o sistema escolar, em expansão restrita, conferia a poucos negros (especialmente os mulatos) a possibilidade de êxito escolar, arremessando-os a expectativas de inserção social ao mundo dos brancos que, entretanto, não poderiam ser atendidas (Costa Pinto, 1953, p. 259).

Com efeito, os trabalhos de Bicudo, Ginsberg e Costa Pinto sugerem que a escola atua como espaço de expressão e ação da discriminação racial que opera como dispositivo para o fracasso escolar. Quando extraordinariamente isso não ocorre e há êxito na trajetória escolar de estudantes negros, sua mobilidade social será tensionada (quando não negada) nas relações sociais mais abrangentes. Isso parece revelador não apenas da ineficiência do sistema educacional, mas também da dificuldade de constituição da realidade escolar como um objeto heuristicamente autônomo na medida em que a dinâmica das relações sociais, assentada sob uma lógica racista que atravessa a sociedade de 84 forma global, torna-a fenômeno derivado. Esse talvez seja um ponto nodal a nos sugerir algumas hipóteses sobre a percepção do estatuto sempre deficitário da sociologia da educação no Brasil.

\section{Dilema entre potencialidades da sociologia no ensino secundário e realidade escolar}

No final dos anos 1940 e início dos 1950, ocorreram debates sobre as possibilidades e finalidades da sociologia na escola secundária que ocuparam sociólogos como Luiz Aguiar da Costa Pinto, Florestan Fernandes, Antonio Candido, além de Donald Pierson, entre outros. As discussões foram reunidas e publicadas na Revista Sociologia (1949) e nos Anais do I Congresso Brasileiro de Sociologia, evento ocorrido em $1954 . .^{5}$

\footnotetext{
Para uma reconstituição detalhada desse debate, recomendo a leitura de Neuhold (2014).
} 
Os textos demonstram que jovens expoentes da primeira geração de cientistas sociais indagaram sobre condições para o ensino das ciências sociais no Brasil, incluindo a pertinência do retorno da sociologia ao ensino secundário. $\mathrm{O}$ assunto foi tema central do Congresso Brasileiro de Sociologia, primeiro item de seu ementário, mencionado nas comunicações de encerramento e de abertura feitas pelo então presidente da Sociedade Brasileira de Sociologia, Fernando de Azevedo (Neuhold, 2014, pp. 179, 229, 227).

Lembremos que a sociologia esteve no currículo obrigatório do curso secundário em todo o território nacional entre os anos de 1931 e 1942. Sua presença na escola naquele período reproduziu tensões e polêmicas na disputa pelo monopólio da explicação da sociedade numa época de recrudescimento do autoritarismo. Os compêndios didáticos surgidos no período são testemunho das variações no gradiente de ideias possíveis acerca da vida social e fixavam, num extremo, a perspectiva orgânica de Fernando de Azevedo e, no outro, a normatividade cristã de Alceu Amoroso Lima (Meucci, 2011).

Nesse sentido, os debates sobre o ensino da sociologia ocorridos no final dos anos 1940 e na primeira metade da década de 1950 se desenvolveram ainda sob o impacto da exclusão da sociologia no sistema escolar (quase em simultâneo à constituição dos primeiros portadores especializados do conhecimento sociológico) e frente à possibilidade de revisão do currículo com a compulsória necessidade de definição de uma a Lei de Diretrizes e Bases da Educação (exigência da nova Constituição promulgada em 1946).

É também uma discussão que sinalizava pretender expurgar as funções que a sociologia escolar desempenhara na ditadura de Vargas e reelaborá-las para o contexto de profissionalização acadêmica da área e democratização do país. Donald Pierson afirmava, nesse sentido, que o grande obstáculo para o ensino da sociologia no Brasil era 
a incompreensão de seu caráter científico, confundido ora com socialismo, ora com reforma social, serviço social ou filosofia social (Pierson, 1949, p. 318).

As posições dos autores nunca foram, porém, consensuais quanto ao retorno da sociologia ao currículo da escola básica: Antonio Candido por exemplo, foi contrário; Costa Pinto, favorável; ao passo que Florestan Fernandes reconheceu potencialidades didáticas do campo de conhecimento em meio a possibilidades concretas bastante limitadas.

Com efeito, podemos dizer que, apesar de distintas posições a respeito da sociologia no ensino secundário, os argumentos dos três autores aqui destacados invariavelmente especulam sobre certas dificuldades que, combinadas, se tornam desafiadoras para a sociologia no nível secundário de ensino: por um lado, a sofisticação da abordagem da ciência social que exige operação complexa de racionalização; por outro, as percepções desfavoráveis que orientam a ação educacional, acrescidas da situação pedagógica e materialmente precária das escolas secundárias brasileiras (Candido, 1949, p. 283; Costa Pinto, 1949, p. 304; Fernandes, 1955b, p. 105).

Não obstante, se Antonio Candido considera a sociologia incompatível com o ambiente escolar, Costa Pinto e Florestan enxergam sua capacidade transformadora potencialmente atuante para o ajustamento de jovens estudantes às demandas reclamadas pela sociedade brasileira.

Vale lembrar que, em 1954, quando Florestan participava do congresso, provavelmente estava em vias de finalizar seu trabalho de coordenação do projeto Unesco/ Revista Anhembi. Em um dos capítulos para o relatório do projeto, intitulado "Cor e estrutura social em mudança", Florestan conclui os resultados de sua pesquisa afirmando que, ainda que a urbanização e o desenvolvimento econômico da cidade de São Paulo estejam efetivamente favorecendo - no nível das relações categóricas e formais - a integração do negro, há também sinais nítidos de manutenção 
de preconceito de cor, inclusive naquelas relações que se fundamentam na simpatia e no afeto. Isso sugere, segundo Florestan, que o preconceito, apesar das transformações em curso, poderia encontrar condições estruturais para sua perpetuação (Fernandes, 1955a, p. 122).

Com efeito, considerando que essas conclusões e o texto sobre ensino da sociologia na escola secundária foi escrito mais ou menos no mesmo período, parece-nos interessante relacionar os argumentos de Florestan acerca da antinomia da sociedade à aspiração de que a sociologia, no ensino secundário, pudesse deliberadamente influenciar ajustamentos sociais reclamados para cumprimento dos ideais democráticos. Chegamos a uma chave que permite vincular "razão sociológica" e democracia em dois planos: na pesquisa empírica e no ensino escolar. Ou seja, numa sociedade em que a sociologia desvenda fatores extrarracionais em atuação, ela tem também a tarefa de promover a consciência racional, requisito importante para adequação das personalidades à sociedade que se deseja.

Pode-se dizer assim que, ao propor o ensino da sociologia na escola, Florestan é exigente: entende o conhecimento sociológico como uma atitude epistemológica e heurística, e também pedagógica, capaz de transformar não apenas personalidades como também o sistema educacional na direção da racionalização. Em sua perspectiva, não se trata de uma mera ciência sofisticada, mas também de um compromisso social muito difícil na medida em que, pela própria natureza das relações sociais, a escola não aparece como um ambiente capaz de favorecer facilmente os fins que Florestan imagina para a disciplina de sociologia. Esse é o dilema posto pelo autor, que conclui o texto sobre a sociologia no ensino secundário de modo inquieto, propondo reflexões acerca das possibilidades para que a área de conhecimento se constitua efetivamente como um "instrumento consciente de mudança social” (Fernandes, 1955b, p. 106). 
Nesse sentido, ao analisar esse debate sobre a sociologia no ensino secundário, a escola não se constitui como um problema analítico, mas como um problema prático que, pelo atraso de suas concepções e pela sua precariedade material, impõe dificuldades para a circulação do pensamento científico (em particular, o conhecimento sociológico), ao mesmo tempo que é, para alguns, também uma área privilegiada para a formação de uma consciência capaz de ajudar na orientação racional das condutas.

\section{A LDB e seus efeitos sobre a pesquisa e a interpretação sociológica}

A tramitação da primeira Lei de Diretrizes e Bases da Educação Brasileira (LDB) ocorreu no período entre os anos de 1946 e 1961. O debate teve duas fases: a primeira, colocava em questão a natureza do pacto federativo, enquanto a segunda, a partir de 1957, referia-se ao confronto a respeito da possibilidade do ensino laico, público, gratuito e universal. ${ }^{6}$

Com efeito, acreditamos que o debate em torno da LDB atualizou dilemas da primeira metade dos anos 1930, opondo, mais uma vez, educadores renovadores aos conservadores. Anísio Teixeira, como também Fernando de Azevedo, nos períodos mais aquecidos da discussão, foram personagens ativos no debate parlamentar, compondo

\footnotetext{
6 No período entre o final da década de 1940 e a primeira metade dos anos 1950 , o impasse teve como protagonistas Clemente Mariani (filiado à União Democrática Nacional [UDN], ministro de Educação e Saúde entre os anos de 1946 e 1950) e Gustavo Capanema (então deputado federal pelo Partido Social Democrático [PSD] e que tinha sido o mais poderoso ministro de Getúlio Vargas, na pasta de Educação e Saúde). Mariani apresentou, em 1949, anteprojeto para a LDB que, no entanto, recebeu parecer desfavorável de Capanema, fato que levou à suspensão da tramitação até 1957. No seu parecer, Capanema tentava desqualificar a possibilidade de interrupção do legado do Estado Novo no campo educacional. O impasse dizia respeito aos moldes do pacto federativo. No anteprojeto original de Mariani, cada estado deveria organizar seu sistema de ensino respeitando certos princípios gerais elaborados pela União. Capanema condenava a proposta de descentralização argumentando que se tratava de uma ameaça à qualidade de ensino e, no limite, à própria ideia de nação (Montalvão, 2011, p. 134).
} 
comissão especial e manifestando-se favoráveis à universalização, laicização e descentralização administrativa, financeira e curricular, entendendo a "diversificação" como um requisito do desenvolvimento cultural da nação. ${ }^{7}$ Para Teixeira, estava em jogo a possibilidade de superação da ossatura institucional do Estado Novo e o ressurgimento do federalismo como um instrumento de administração pública democrática (Montalvão, 2011, p. 122).

No início de 1959, as articulações em torno da elaboração da LDB que tramitava na Câmara Federal caminhavam para momentos decisivos quando Carlos Lacerda apresentou substitutivo que previa subsídio do Estado às escolas privadas. Diante disso, educadores renovadores publicaram uma carta que ficou conhecida como "Manifesto dos educadores novamente convocados”, em referência ao manifesto lançado em 1932.

Ficou também conhecida a atuação de Florestan Fernandes, que se tornou especialmente sensível ao tema após o substitutivo de Lacerda. Florestan articulou moções de repúdio à Câmara de Deputados e aos senadores da República, organizou a adesão de intelectuais e da Câmara de Vereadores de São Paulo à causa, aproximou-se de movimentos de estudantes secundaristas e de cursos superiores. Dedicou-se, enfim, ao que chamou de "gradativa radicalização do movimento” (Fernandes, 1966, p. 347).

Além disso, o sociólogo denunciava os riscos que envolviam a aprovação da lei em suas colunas para O Estado de S. Paulo. Os textos foram, mais tarde, reunidos num capítulo do livro Educação e sociedade no Brasil intitulado "A conspiração contra

\footnotetext{
7 Em 1958, a temperatura se elevou tanto que bispos do Rio Grande do Sul pediram ao presidente da República, Juscelino, a cabeça de Anísio Teixeira em uma carta cujo primeiro signatário era o arcebispo Vicente Scherer, de Porto Alegre. A carta ficou conhecida como "Manifesto dos bispos" e acusava Anísio de favorecer uma revolução social, transformando a República brasileira numa República socialista por meio da implantação exclusiva de sistemas de ensino oficiais em todo o país. A carta foi publicada pela Revista Brasileira de Estudos Pedagógicos, órgão oficial do Instituto de Estudos Pedagógicos (Inep) que Anísio presidia. Ele chegou a ser informado de sua demissão, mas protestos de acadêmicos e jornalistas evitaram esse desfecho.
} 
a escola pública”. Em conjunto, os artigos permitem acompanhar seus movimentos a cada tramitação da lei. Por um lado, Florestan acusava o Estado de não agir em consonância com o interesse coletivo, e, por outro, dizia-se decepcionado em relação aos intelectuais que voltaram as costas para o assunto da escola pública (Fernandes, 1966, p. 376).

Seus textos têm um sentido dramático de urgência e de decepção. Para ele, a LDB, que se apresentara, antes, como uma oportunidade, transformara-se, desde o substitutivo, num pesadelo. Florestan argumenta que a tramitação demonstrava que, basicamente, não havia lealdade à ordem democrática em formação. Ao contrário, representantes políticos pactuavam lealdade ao antigo regime (Fernandes, 1966, p. 351).

Nesse sentido, a tramitação da LDB reinseriu o debate dos anos 1930 em novas condições que foram se delineando mais nítidas ao longo da década, à medida que os problemas e as dificuldade se agravavam. Em meio à tentativa de construção de uma institucionalidade democrática, com o debate social e sociológico tensionado pela desigualdade social aprofundada pela velocidade sem precedentes do desenvolvimento urbano e industrial, o tema da definição do sistema educacional ganhava contornos de oportunidade histórica única, que exigia ação intelectual e política. Educadores e cientistas sociais sentiram-se especialmente convocados.

No que se refere à ação intelectual no campo da sociologia, é possível considerar que, de início, o impasse acerca da natureza do pacto federativo na conformação do sistema educacional motivou a criação do Centro Brasileiro de Pesquisas Educacionais (CBPE) por Anísio Teixeira em 1955. ${ }^{8}$ Anísio parecia querer fundamentar, por meio dos estudos do CBPE, uma visão complexa sobre a diversidade do país e, com isso, reforçar argumentos em favor de sua posição pela descentralização do sistema.

8 O CBPE era órgão subordinado ao Inep, dirigido desde 1952 por Anísio Teixeira. 
Localizado no Rio de Janeiro, o CBPE foi composto por unidades locais - os chamados "centros regionais" sediados em Recife, Salvador, Belo Horizonte, São Paulo e Porto Alegre. Do ponto de vista organizacional, todos os centros tinham uma Divisão de Estudos Educacionais (referidos à escola) e uma Divisão de Estudos Sociais (referidos à sociedade em seu caráter amplo), além de uma Divisão de Formação do Magistério (Mariani, 1982; Xavier, 1999; Ferreira, 2008).

A criação das divisões de estudos educacionais e sociais provavelmente se fundamenta na ideia de que pesquisas educacionais e sociológicas se distinguiam, mas eram indissociáveis para a elaboração de uma nova política educacional capaz de se ajustar às exigências do desenvolvimento social e cultural das diversas regiões do país.

A ironia é que alguns estudos sociológicos do CBPE se afastaram do tema da educação e, em vez de ajudarem a compor a imagem da diversidade brasileira assentada sobre aspectos culturais, reforçaram uma imagem de país continental que tem a marca da unidade assentada sobre o legado da escravidão e do racismo. Basta apenas lembrar que, na segunda metade dos anos 1950, o CBPE financiou nova fase de pesquisas sobre relações raciais, agora na região Sul do país. Foi realizada pelos orientandos de Florestan Fernandes, Octavio Ianni e Fernando Henrique Cardoso, em Florianópolis, Curitiba e Pelotas. Nessa nova fase do projeto, a dimensão da socialização escolar ou do sistema educacional não apareceu como objeto de preocupação. Os pesquisadores privilegiaram a compreensão histórica das condições de transição na Abolição e os aspectos da estrutura ocupacional vigente. ${ }^{9}$

\footnotetext{
9 No estudo feito por Cardoso e Ianni em Florianópolis, publicado sob o título "Cor e mobilidade social em Florianópolis" (1960), há aplicação de surveys em estabelecimentos escolares públicos e privados a fim de identificar o nível de discriminação (Cardoso e Ianni, 1960, p. 169). Não obstante, a escola e a ação escolar não aparecem sequer problematizadas, mas, sim, como um "cenário", parte de uma totalidade social constituída pelas relações de trabalho e de lazer, pela dinâmica de distribuição das moradias e pelos vínculos familiares.
} 
Entretanto, houve, sem dúvida, estudos financiados pelo CBPE que, hoje, relacionaríamos ao campo da sociologia da educação ou da sociologia escolar. Na agenda da instituição, encontramos numerosos trabalhos sociológicos sobre escola, infância e desempenho escolar, alguns dos quais monografias dedicadas a desestabilizar a ideia de um Brasil que marcha linearmente rumo à completude dos efeitos da modernização burguesa. ${ }^{10}$

Pelos limites deste artigo, vamos nos ater, mais uma vez, a São Paulo. Vale a pena lembrar, em particular, o trabalho pouco conhecido de Luiz Pereira que resultou no livro $A$ escola numa área metropolitana (apresentado em 1960 à cadeira I de sociologia da Universidade de São Paulo [USP]). Esse trabalho, orientado por Florestan Fernandes no momento mesmo em que se acirrava o embate sobre a LDB, é uma reflexão sobre os impasses da sociedade brasileira a partir de uma escola primária situada em Santo André, subúrbio industrial de São Paulo, então com quase 200 mil habitantes (dos quais cerca de 35 mil operários).

É um trabalho monográfico. Pereira descreve a escola em detalhes (que tinha, então, 1.864 alunos matriculados) e também seu entorno. Situa-a numa zona urbana marginal, onde cresciam loteamentos que fixavam precariamente famílias pobres vindas do meio rural do interior do estado ou do Nordeste do país, atraídas por melhores condições de ascensão social (Pereira, 1967, p. 28).

Para Pereira, ocorria ali um notável processo de ajustamento das ações em direção à racionalização que era impulsionado pela indústria. Ou seja, a indústria forçava a competição econômica dos indivíduos e exigia certificação escolar,

\footnotetext{
10 Destacam-se os trabalhos de Josidelth Gomes Consorte (1959), no Rio de Janeiro, e de Antonio Candido (1956; 1957), Juarez Brandão Lopes (1959) e Dante Moreira Leite (1959), em São Paulo. Sobre esses trabalhos, recomendamos a leitura dos artigos de Beisiegel (2013) e Freitas (2014).
} 
tornando a escola primária etapa compulsória da vida dos garotos filhos de pais que eram, em sua maioria, analfabetos.

No entanto, a despeito do processo racionalizador, Pereira nos mostra que tensões renitentes entre burocracia e patrimonialismo norteavam as práticas mais ordinárias de diretores, professores, serventes e pais de alunos. A distribuição pessoalizada de cargos pela Secretaria de Ensino, a prática cotidiana da autoridade pessoal do diretor em exercício, o tratamento doméstico conferido aos serventes, as expectativas dos professores contrárias às regras burocráticas e as aspirações bastante limitadas dos pais em relação à vida escolar dos filhos são aspectos descritos em seus pormenores por Pereira, incongruentes com as aspirações por uma sociedade democrática e emergente.

O trabalho de Pereira nos mostra, enfim, que, no final dos anos 1950, houve um avanço nas pesquisas sociológicas no campo da educação (ou da escola em particular). Sua monografia é testemunho de que, no período em que os impasses para a formulação de um sistema educacional gratuito, público e laico se tornaram mais nítidos, as pesquisas acerca da realidade escolar se colaram aos estudos que visavam reconhecer resistências à mudança social, sobretudo nos contextos de transformação urbana muito acelerada (Freitas, 2014, p. 686). Nesse sentido, a escola emergiu como unidade analítica que problematiza privilegiadamente tensões entre modos de agir racional e tradicional.

Ao final deste artigo, podemos consolidar algumas hipóteses. É possível dizer que o tema da educação e o modo como se articulou à agenda nascente de pesquisas em sociologia sempre estiveram conectados à política num sentido abrangente, fundamentado no compromisso com as condições de desenvolvimento de ideais igualitários. A sociologia 
era considerada uma atividade analítica capaz de questionar a realidade educacional e apontar fatores extrarracionais vigentes, mas também uma ação pedagógica em potencial capaz de, dilematicamente, em condições escolares precárias, auxiliar na constituição da consciência racional da sociedade.

Constatamos também que a tramitação da LDB teve impacto importante para a elaboração da consciência a respeito da sociedade brasileira, com reflexos, inclusive, no fomento à pesquisa sociológica e na constituição da escola como unidade heurística, ao mesmo tempo que permitia reconhecer os impasses para a racionalização e a democratização no Brasil.

Com efeito, durante os anos 1950, o acirramento do debate sobre a LDB e o modo como esse debate foi percebido como evidência das resistências à democratização e laicização da sociedade fizeram crescer o interesse e as possibilidades das pesquisas sobre estudantes, escolas e o sistema educacional - dimensões da vida social entendidas como uma espécie de epifenômeno das limitações ao processo de modernização das relações sociais.

Em especial a criação do Centro Brasileiro de Pesquisas Educacionais favoreceu (ainda que precariamente) uma via institucional favorável à pesquisa sociológica. Ainda que, de início, ele tenha sido inspirado na ideia da diversidade cultural como fundamentação da descentralização do sistema escolar, logo se impôs uma discussão sobre os fundamentos e estatutos da desigualdade social, cujas modulações eram renitentes mesmo nos contextos de urbanização acelerada.

Verificamos também que o tema das relações raciais foi visto da perspectiva da realidade das escolas. O preconceito verificado entre estudantes parece ter sido considerado um fenômeno que se produz na escola, mas também precede e ultrapassa a socialização escolar. Nessa perspectiva, o problema das relações raciais foi considerado o impasse nodal 
da sociedade brasileira, que exigia empenho de parte notável da primeira geração de cientistas sociais.

Essa hipótese sugere que o alcance do tema das relações raciais para a constituição da sociologia teve, no Brasil, papel equivalente à sociologia da educação na França ou à sociologia do desvio nos Estados Unidos. Se para sociólogos estadunidenses o estudo das formas de controle social gestadas na sociabilidade urbana serviam para contestar as noções de patologia social de grupos imigrantes marginalizados, para os franceses a escola foi o objeto mais precioso que permitiu discutir os impasses relativos aos ideais de igualdade republicana na França e desmistificar os ideais de meritocracia. Ao passo que, no Brasil, esse papel desmistificador da sociologia coube, sobretudo, aos estudos sobre as relações raciais que precisaram pôr em xeque o potente mito de "democracia racial".

Possivelmente, decorre disso o suposto caráter deficitário e periférico da produção em sociologia da educação no Brasil, país onde a escola e o sistema de educação nunca ocultaram o caráter de conservação do status quo. Coube menos à pesquisa sociológica desnaturalizar a educação escolar do que discutir os limites e possibilidades com os quais a escola, atravessada por formas de dominação tradicional, poderia se constituir como um locus da mudança social. Nesse sentido, a sociologia se apresentava não apenas como campo científico, mas como ação pedagógica potencialmente transformadora.

\section{Simone Meucci}

Doutora em sociologia pela Universidade Estadual de Campinas, professora do Departamento de Sociologia da Universidade Federal do Paraná. Realiza pesquisas na área de pensamento social brasileiro e história do ensino da sociologia no Brasil. Publicou os livros Institucionalização da sociologia no Brasil: primeiros manuais e cursos (Hucitec, 2011) e Artesania da sociologia no Brasil: interpretações e contribuições de Gilberto Freyre (Appris, 2015). 


\section{Bibliografia}

ANDREWS, George Reis. 1997. Democracia racial brasileira 1900-1990: um contraponto americano. Estudos Avançados, v. 11, n. 30, pp. 95-115. Disponível em: https:/ /bit.ly/3iHlOgu. Acesso em: 27 ago. 2019. BASTOS, Elide Rugai. 2007. Unesco/Anhembi: um debate sobre a situação do negro no Brasil. In: PEREIRA, Cláudio Luiz; SANSONE, Livio (org.). Projeto Unesco no Brasil. Salvador: EDUFBA. pp. 251-269. BEISIEGEL, Celso de Rui. 2013. Os primeiros tempos de pesquisa em sociologia da educação na USP. Educação e Pesquisa, v. 39, n. 3, pp. 589-607. Disponível em: https:/ /bit.ly/3as4auc. Acesso em: 25 ago. 2019.

BICUDO, Virgínia Leone. 1955. Atitudes de alunos dos grupos escolares em relação com a cor de seus colegas. In: FERNANDES, Florestan; BASTIDE, Roger. (org.). Relações raciais entre negros e brancos em São Paulo. São Paulo: Anhembi. pp. 227-310.

CANDIDO, Antonio. 1949. Sociologia: ensino e estudo. Sociologia: Revista Didática e Científica, n. 11, v. 3.

CANDIDO, Antonio. 1956. A estrutura da escola. Separata do Boletim CBPE, Brasília: Inep.

CANDIDO, Antonio. 1957. As diferenças entre o campo e a cidade e seu significado para a educação. Pesquisa e Planejamento, CRPE-SP, v. 1, pp. $107-128$.

CARDOSO, Fernando Henrique; IANNI, Octavio. 1960. Cor e mobilidade social em Florianópolis. São Paulo: Companhia Editora Nacional.

CONSORTE, Josildeth G. 1956. A educação nos estudos de comunidades. Educação e Ciências Sociais, v. 1, n. 2, pp. 63-106.

COSTA PINTO, Luís A. 1949. Ensino da sociologia nas escolas secundárias. Sociologia: Revista Didática e Científica, n. 11, v. 3, pp. 290-308.

COSTA PINTO, Luís A. 1953. O negro no Rio de Janeiro: relações de raças numa sociedade em mudança. São Paulo: Companhia Editora Nacional.

CUNHA, Luiz Antônio. 1992. A educação na sociologia: um objeto rejeitado. Caderno Cedes, n. 27, pp. 9-22.

CUNHA, Renata Rocha Tsuji da; SANTOS, Alessandro de Oliveira dos. 2014. Aniela Meyer Ginsberg e os estudos de raça/etnia e intercultura no Brasil. Psicologia USP, v. 25, n. 3, pp. 317-329. Disponível em: https://bit.ly/3aoGUgQ. Acesso em: 22 ago. 2019.

FERNANDES, Florestan. 1955a. Côr e estrutura social em mudança. In: FERNANDES, F.; BASTIDE, R. Relações raciais ente negros e brancos em São Paulo. São Paulo: Anhembi. pp. 77-162. 
FERNANDES, Florestan. 1955b. O ensino da sociologia na escola secundária brasileira. In: CONGRESSO BRASILEIRO DE SOCIOLOGIA, 1., São Paulo. Anais [...]. São Paulo: Sociedade Brasileira de Sociologia.

FERNANDES, Florestan. 1966. Educação e sociedade no Brasil.

São Paulo: Dominus.

FERREIRA, Márcia Santos. 2008. Os Centros de Pesquisas Educacionais do Inep e os estudos em ciências sociais sobre a educação no Brasil. Revista Brasileira de Educação, v. 13, n. 38, pp. 279-292. Disponível em: https://bit.ly/3iJDGHU. Acesso em: 23 ago. 2019.

FREITAS, Marcos Cezar de. 2014. Desempenho e adaptação da criança pobre à escola: o padrão de pesquisa do CRPE-SP. Educação e Pesquisa, v. 40, n. 3, pp. 683-698. Disponível em: https://bit.ly/2XVZaJx. Acesso em: 31 ago. 2019.

GINSBERG, Aniela. 1955. Pesquisa sobre as atitudes de um grupo de escolares de São Paulo em relação com as crianças de côr. In: FERNANDES, Florestan; BASTIDE, Roger. Relações raciais entre negros e brancos em São Paulo. São Paulo: Anhembi.

LEITE, Dante Moreira. 1959. A promoção automática e a adequação do currículo ao desenvolvimento do aluno. Pesquisa e Planejamento, v. 3, pp. 15-26.

LOPES, Juarez R. Brandão. 1959. Estrutura social e educação no Brasil. Educação e Ciências Sociais, v. 4, n. 10.

MAIO, Marcos Chor. 1999. O Projeto Unesco e a agenda das ciências sociais no Brasil dos anos 40 e 50. Revista Brasileira de Ciências Sociais, v. 14, n. 41, pp. 141-158. Disponível em: https://bit.ly/3gYJM6q. Acesso em: 26 ago. 2019.

MAIO, Marcos Chor. 2010. Educação sanitária, estudos de atitudes raciais e psicanálise na trajetória de Virgínia Leone Bicudo. Cadernos Pagu, n. 35, pp. 309-355. Disponível em: https://bit.ly/33Wgj9P.

Acesso em: 26 ago. 2019.

MAIO, Marcos Chor. 2015. Medindo o preconceito racial no Brasil:

Aniela Ginsberg e o estudo das atitudes raciais. Revista Latinoamericana de Psicopatologia Fundamental, v. 18, n. 4, pp. 728-742. Disponível em: https://bit.ly/341J598. Acesso em: 22 ago. 2019.

MARIANI, Maria Clara. 1982. Educação e ciências sociais: o Instituto Nacional de Estudos e Pesquisas Educacionais. In: SCHWARTZMAN, S. (ed.). Universidades e instituições científicas no Rio de Janeiro. Brasília: CNPq. MARTINS, Carlos Benedito; WEBER, Silke. 2010. Sociologia da educação: democratização e cidadania. In: MARTINS, C. B.; MARTINS, H. H. T. S. (org.). Sociologia. São Paulo: Anpocs. 
MEUCCI, Simone. 2011. Institucionalização da sociologia no Brasil: primeiros manuais e cursos. São Paulo: Hucitec.

MONTAlVÃO, Sérgio de Souza. 2011. Por uma história política da educação: a Lei de Diretrizes e Bases e democracia na Terceira República (1946-1961).

Tese de Doutorado em História, Política e Bens Culturais. Rio de Janeiro: CPDOC/FGV. Disponível em: https://bit.ly/2Y1vNp2. Acesso em: 12 ago. 2019.

MORAES, Amaury Cesar. 2003. Licenciatura em ciências sociais e ensino de sociologia: entre o balanço e o relato. Tempo Social, v. 15, n. 1, pp. 5-20. Disponível em: https://bit.ly/3400SNV. Acesso em: 23 ago. 2019.

NASCIMENTO, Abdias do. 2004. Teatro experimental do negro: trajetória e reflexões. Estudos Avançados, v. 18, n. 50, pp. 209-224. Disponível em: https://bit.ly/2Q5WViB. Acesso em: 1ํoset. 2019.

NEUHOLD, Roberta dos Reis. 2014. Sociologia do ensino de sociologia: os debates acadêmicos sobre a constituição de uma disciplina escolar. Tese de Doutorado em Educação. São Paulo: Faculdade de Educação da USP. Disponível em: https://bit.ly/2E2MZna. Acesso em: 25 ago. 2019. NEVES, Clarissa Baeta. 2002. Estudos sociológicos sobre educação no Brasil. In: MICELI, S. (org.). O que ler na ciência social brasileira 1970-2002: sociologia. São Paulo: Sumaré.

OLIVEIRA, Amurabi; SILVA, Camila Ferreira da. 2016. A sociologia e os sociólogos da educação no Brasil. Revista Brasileira de Ciências Sociais, v. 31, n. 91, pp. 1-15. Disponível em: https://bit.ly/2DQUwpa. Acesso em: 23 ago. 2019.

PEREIRA, Luiz. 1967. A escola numa área metropolitana. São Paulo: Pioneira. PIERSON, Donald. 1949. Difusão da ciência sociológica na escola. Sociologia: Revista Didática e Científica, n. 11, v. 3.

PNUD. IPEA. 1996. Relatório sobre desenvolvimento humano no Brasil. Disponível em: https://bit.ly/3g1p1pw. Acesso em: 23 ago. 2019. SANTOS, Elisângela da Silva. 2018. O legado de Virgínia Leone Bicudo para a sociologia da infância no Brasil. Cadernos de Pesquisa, v. 48, n. 170, pp. 1194-1217. Disponível em: https://bit.ly/3gXuMpB. Acesso em: 26 ago. 2019.

SOBRAL, Fernanda. 2013. A educação na pós-graduação em sociologia: um objeto escondido? Estudos Sociais, n. 1, v. 19.

SOUZA, Marcelo Medeiros Coelho de. 1999. O analfabetismo no Brasil sob enfoque demográfico. Cadernos de Pesquisa, n. 107, pp. 169-186. Disponível em: https://bit.ly/2PPMJdK. Acesso em: 22 ago. 2019. XAVIER, Libânia Nacif. 1999. O Brasil como laboratório: educação e ciências sociais no projeto do Centro Brasileiro de Pesquisas Educacionais. Bragança Paulista: Edusf. 


\section{ENCAIXES, DESENCAIXES E BLOQUEIOS: SOCIOLOGIA E EDUCAÇÃO NO BRASIL DA DÉCADA DE 1950}

\section{SIMONE MEUCCI}

Resumo: Este artigo discute a relação entre educação e sociologia na década de 1950 no Brasil. Para isso, elegemos três eixos empíricos: a) as investigações sobre relações raciais conhecidas, como "Projeto Unesco", no período da rotinização das pesquisas sociológicas no Brasil; b) o debate sobre sociologia no ensino médio envolvendo, desde o final dos anos 1940 e início dos 1950, alguns dos primeiros portadores especializados da área; c) o processo tramitação da Lei de Diretrizes e Bases da Educação ocorrida no período. Esses eixos são vistos como influxos recíprocos que permitem verificar aspectos heurísticos e políticos da apropriação do tema da educação pelos sociólogos. Verificamos, ao final, que pesquisas e debates relativos ao sistema educacional e à socialização escolar se subordinaram à problematização das relações raciais e à reflexão acerca dos bloqueios para a mudança social.

Palavras-chave: Sociologia e Educação; Relações Raciais; LDB.

\section{CONNECTIONS, DISCONNECTIONS AND BLOCKS: SOCIOLOGY AND EDUCATION IN 1950S BRAZIL}

Abstract: This article discusses the relation between education and sociology in 1950s Brazil. We chose three empirical axes: a) the investigations on racial relations known as "Projeto Unesco" in the period of sociological research routinization in Brazil; b) the debate about sociology in high school involving some young researchers in the field since the late 1940s and early 1950s; c) the discussion about the "Lei de Diretrizes e Bases da Educação" which occurred during this period. These axes are seen as reciprocal inflows that allow the verification of heuristic and political aspects in the 
appropriation of the theme of education by sociologists. Lastly, we verified that studies and discussion related to the educational system and school socialization were subordinated to the problematization of race relations and the reflection about the blocks in social change. Keywords: Sociology and Education; Race Relations; LDB.

Recebido: 23/09/2019 Aprovado: 05/08/2020 